\title{
Water vapour profiles from SCIAMACHY solar occultation measurements derived with an onion peeling approach
}

\author{
S. Noël, K. Bramstedt, A. Rozanov, H. Bovensmann, and J. P. Burrows \\ Institute of Environmental Physics, University of Bremen, FB 1, P.O. Box 330440, 28334 Bremen, Germany \\ Received: 9 November 2009 - Published in Atmos. Meas. Tech. Discuss.: 15 January 2010 \\ Revised: 16 April 2010 - Accepted: 26 April 2010 - Published: 29 April 2010
}

\begin{abstract}
A new retrieval method has been developed to derive water vapour number density profiles from solar occultation measurements of the SCanning Imaging Absorption spectroMeter for Atmospheric CHartographY (SCIAMACHY). This method is intentionally kept simple and based on a combination of an onion peeling approach with a modified DOAS (Differential Optical Absorption Spectroscopy) fit in the wavelength region around $940 \mathrm{~nm}$. Reasonable resulting water vapour profiles are currently obtained in the altitude range $15-45 \mathrm{~km}$. Comparisons of the SCIAMACHY profiles with water vapour data provided by the Atmospheric Chemistry Explorer Fourier Transform Spectrometer (ACE-FTS) show an average agreement within about 5\% between 20 and $45 \mathrm{~km}$. SCIAMACHY water vapour data tend to be systematically higher than ACE-FTS. These results are in principal confirmed by comparisons with water vapour profiles derived from model data of the European Centre for Medium Range Weather Forecasts (ECMWF), although ECMWF concentrations are systematicly lower than both corresponding SCIAMACHY and ACE-FTS data at all altitudes.
\end{abstract}

\section{Introduction}

Water vapour is the most important greenhouse gas and plays a key role in atmospheric chemistry and transport. Most of the water vapour is located in the troposphere where it significantly contributes to weather and climate. Because the tropopause acts as a cold trap, the water vapour density in the stratosphere is significantly lower and decreases rapidly with

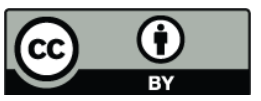

Correspondence to: S. Noël

(stefan.noel@iup.physik.uni-bremen.de) increasing altitude. However, the amount of stratospheric water vapour plays an important role in the generation of Polar Stratospheric Clouds (PSCs), which in turn influence strongly the amount of ozone in polar regions.

Trends in stratospheric water vapour are determined by methane oxidation, transport through the tropopause and by the Brewer-Dobson circulation (see Dhomse et al., 2008, and references therein). To separate the various effects there is a clear need for global long term measurements of lower stratospheric water vapour, as it can be provided by satellite measurements.

In the past, long-term stratospheric water vapour data sets have been provided by the Stratospheric Aerosol and Gas Experiment (SAGE) II and III (Thomason et al., 2004, 2007), the Halogen Occultation Experiment (HALOE; Russell et al., 1993) and the Polar Ozone and Aerosol Measurement (POAM III; Nedoluha et al., 2002). Unfortunately, all these instruments discontinued operations in 2005/2006. Currently, water vapour profiles are for example provided by limb measurements of the Sub-Millimeter Radiometer (SMR) on the Odin satellite (Murtagh et al., 2002; Urban et al., 2007), the Microwave Limb Sounder (MLS) on Aura (see e.g. Barnes et al., 2008) and the Michelson Interferometer for Passive Atmospheric Sounding (MIPAS, Fischer et al., 2008; Milz et al., 2009) on ENVISAT. Profile information about water vapour can also be derived from nadir measurements, like those of the Atmospheric Infrared Sounder (AIRS) and the Advanced Microwave Sounding Unit (AMSU) on Aura, see e.g. Aumann et al. (2003); Hagan et al. (2004). Furthermore, the GOMOS (Global Ozone Monitoring by Occultation of Stars) instrument (Kyrölä et al., 2004), also on ENVISAT, and the Atmospheric Chemistry Experiment (ACE) on SCISAT-1 (Bernath et al., 2005), measuring in solar occultation geometry, also provide water vapour profiles.

Published by Copernicus Publications on behalf of the European Geosciences Union. 


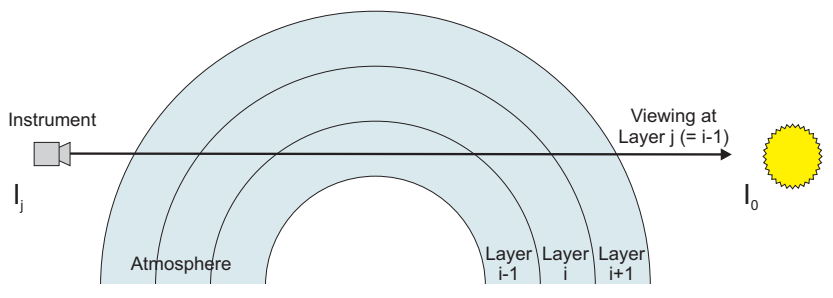

Fig. 1. The solar occultation viewing geometry.

The SCanning Imaging Absorption spectroMeter for Atmospheric CHartographY (SCIAMACHY; Bovensmann et al., 1999) is - as MIPAS and GOMOS - part of the payload of the European Environmental Satellite ENVISAT which was launched in 2002. SCIAMACHY performs spectral measurements in nadir, limb and lunar/solar occultation geometry, covering almost continuously the wavelength range between about 220 and $2400 \mathrm{~nm}$ (Bovensmann et al., 1999). From these measurements column densities and profiles of various atmospheric constituents are derived (see e.g. Piters et al., 2006), among these also water vapour columns from nadir measurements (see e.g. Noël et al., 2004, 2005). However, up to now no water vapour profile data product from SCIAMACHY exists, although there are first successful attempts to derive such profiles from SCIAMACHY limb data.

In this paper a new method to derive water vapour profiles from SCIAMACHY solar occultation data is presented. Retrievals of atmospheric trace gas profiles from limb or occultation measurements are often based on the optimal estimation (OE) method (see e.g. Rodgers, 1990). This method has proven to be appropriate for this purpose, as it in general produces reliable results which compare well with independent data, see e.g. Rozanov et al. (2005, 2007), Palm et al. (2005), Meyer et al. (2005) or Amekudzi et al. (2005) for examples of (especially SCIAMACHY) retrievals using the $\mathrm{OE}$ method in different viewing geometries. The OE approach usually involves an iterative process where radiative transfer calculations are required in each step. This makes OE methods relatively time consuming, which may become critical if large data sets - like those provided by satellites - need to be analysed. In many cases - like for limb applications in the UV/Vis/NIR, where multiple scattering plays a large role - such an iterative radiative transfer scheme can not be avoided. Alternatively some retrieval methods (see e.g. Kühl et al., 2008) use a two-step approach which separates the derivation of slant column densities of the respective absorber from the inversion. Another method used in the analysis of limb data is the Global Fit approach (Carlotti, 1988) in which a nonlinear least-squares fit is applied simultaneously to the spectra for all tangent heights.

In solar occultation geometry, the measured quantity is not the scattered earthshine but the direct transmission of solar light. In this situation, the sun is directly in the field of view
(FOV) of the instrument and intensities are large. The contribution of light scattered from outside the FOV into the instrument can be neglected. The accuracy of multiple scattering is therefore not as critical for retrievals from occultation measurements as for those from limb scattered radiation. However, radiative transfer calculations remain one limiting factor for the speed of the retrieval, especially in the case of so called line absorbers like water vapour, which require high spectral resolution. Taking these considerations into account, the water vapour profile retrieval method described in this paper is based on an onion peeling approach (Russell and Drayson, 1972) to derive water vapour densities starting from the upper atmospheric layers downwards. In each layer a method based on modified DOAS (Differential Optical Absorption Spectroscopy) (Perner and Platt, 1979; Burrows et al., 1999; Noël et al., 2004) is used to derive the corresponding water vapour density along the line of sight using a pre-calculated radiative transfer data base. In addition as DOAS strictly is applicable only in the optically thin case, a correction accounting for the non-linearity of the water vapour absorption (arising from non-resolved spectral lines) is applied.

The retrieval method is explained in more detail in the following section. In Sect. 3 the application of the method to SCIAMACHY data is described. The results and a first validation by comparison with independent data are then given in Sects. 4 and 5, followed by a discussion of errors in Sect. 6 .

\section{Retrieval method}

\subsection{General approach}

The profile retrieval method is based on an onion peeling approach in which the atmosphere is divided into a number $N_{\text {layer }}$ of horizontal layers. The retrieval starts at the top layer and proceeds downwards, taking into account at each altitude the results of the upper layers. In solar occultation geometry the instrument is looking directly to the sun through the atmosphere (see Fig. 1). The viewing geometry is therefore well defined. Because of the large intensities of the directly transmitted beam no multiple scattering processes need to be considered.

The basic premise is that - assuming a horizontally homogeneous atmosphere - the absorption of light along a light path transecting the whole atmosphere may be written as the sum of the absorption of the individual altitude layers:

$\ln \frac{I_{j}}{I_{0}}=P_{j}-\sum_{i=j}^{N_{\text {layer }}} \tau_{i j}$

where all quantities are functions of wavelength. $I_{0}$ is the unattenuated solar intensity, usually derived from measurements at high tangent altitudes (larger than $100 \mathrm{~km}$ ), where the influence of the atmosphere is negligible. $\tau_{i j}$ denotes 
the optical depth of an absorber (i.e. water vapour) resulting from absorption in a layer $i$ for an instrument looking at tangent altitude $j . I_{j}$ is the corresponding measured spectrum reaching the instrument under these viewing conditions, and $I_{j} / I_{0}$ is the corresponding transmission. Note that because only the directly transmitted light is taken into account, the signal $I_{j}$ is not affected by layers below the tangent height $j . P_{j}$ describes a low (in our case 2 nd) order polynomial by which all broadband spectral features (arising e.g. from Mie or Rayleigh scattering) are taken into account. This resembles the well-known Differential Optical Absorption Spectroscopy (DOAS) approach (Perner and Platt, 1979) which is quite commonly used in the retrieval of nadir measurements (see e.g. Burrows et al., 1999). Therefore we call our method "Onion Peeling DOAS".

The spectral range used in the retrieval is $928 \mathrm{~nm}$ to $968 \mathrm{~nm}$. This wavelength range has been chosen, because there the water vapour absorption is on the one hand large enough for stratospheric retrievals and on the other hand saturation effects are not too strong. Between $928 \mathrm{~nm}$ and $968 \mathrm{~nm}$ mainly water vapour absorbs, but there is also a small absorption by ozone, which is also considered in the retrieval (see below).

\subsection{Convolution effects}

Let $I_{j}^{0}$ be the spectrum measured by an instrument looking at tangent height $j$ in the case that the atmosphere does not contain the absorber for which the partial optical depths $\tau_{i j}$ are given. In this case, $\ln \frac{I_{j}^{0}}{I_{0}}=P_{j}$, and Eq. (1) may be rewritten as:

$\ln \frac{I_{j}^{0}}{I_{j}}=\sum_{i=j}^{N_{\text {layer }}} \tau_{i j}$

This equation only holds in the case that the spectral structures are completely resolved by the measuring instrument. In general, the measured quantity is the atmospheric spectrum convoluted by the instrument spectral response function, also called the instrument slit function. If we denote with \langle\rangle this convolution, the left side of Eq. (2) becomes when using measured spectra:

$\ln \frac{\left\langle I_{j}^{0}\right\rangle}{\left\langle I_{j}\right\rangle}$

which is not identical to the convolution of Eq. (2):

$\ln \frac{\left\langle I_{j}^{0}\right\rangle}{\left\langle I_{j}\right\rangle} \neq\left\langle\ln \frac{I_{j}^{0}}{I_{j}}\right\rangle=\left\langle\sum_{i=j}^{N_{\text {layer }}} \tau_{i j}\right\rangle=\sum_{i=j}^{N_{\text {layer }}}\left\langle\tau_{i j}\right\rangle$

To compensate for this, we define a "corrected" partial optical depth $\tau_{i j}^{\mathrm{c}}$ as:

$\tau_{i j}^{\mathrm{c}}:=\left\langle\tau_{i j}\right\rangle c_{j}^{\mathrm{conv}}$

with

$$
c_{j}^{\mathrm{conv}}:=\frac{\ln \frac{\left\langle I_{j}^{0}\right\rangle}{\left\langle I_{j}\right\rangle}}{\left\langle\ln \frac{I_{j}^{0}}{I_{j}}\right\rangle}
$$

which leads to the following modified version of Eq. (1) which is also fulfilled for convoluted spectra:

$\ln \frac{\left\langle I_{j}\right\rangle}{\left\langle I_{0}\right\rangle}=P_{j}-\sum_{i=j}^{N_{\text {layer }}} \tau_{i j}^{\mathrm{c}}$

Note that Eqs. (1) and (7) are equivalent in the case that the atmospheric spectral structures are much broader than the instrument slit function. However, since the SCIAMACHY instrument does not resolve the individual water vapour lines this correction needs to be considered.

\subsection{Density retrieval}

In the optically thin case, the optical depth $\tau_{i j}$ would be proportional to the number density $n_{i}$, i.e. the concentration of the absorber in layer $i$, the absorption cross section and the length of the corresponding light path.

The relation between a modelled optical depth $\tau_{i j}^{\text {ref }}$ and a real (measured) one $\tau_{i j}$ is therefore given by:

$a_{i}:=\frac{n_{i}}{n_{i}^{\mathrm{ref}}}=\frac{\tau_{i j}}{\tau_{i j}^{\mathrm{ref}}}$

This leads to:

$\ln \frac{I_{j}^{\mathrm{M}}}{I_{0}^{\mathrm{M}}}=P_{j}-\sum_{i=j}^{N_{\text {layer }}} \tau_{i j}^{\mathrm{ref}} a_{i}$

where $\tau_{i j}^{\text {ref }}$ has to include the convolution correction factor $c_{j}^{\text {conv }}$ and $I_{j}^{\mathrm{M}}$ and $I_{0}^{\mathrm{M}}$ are the measured spectra at instrument spectral resolution.

Unfortunately, for water vapour in the spectral range considered here the optically thin case can not be assumed. Furthermore, saturated and non-saturated water vapour absorption lines are not resolved by the SCIAMACHY. As a consequence, the relation between optical depth and number density becomes non-linear. This so-called saturation effect is taken into account by an additional correction factor $c_{i}$ which is a function of (only) density and altitude. $c_{i}$ is currently considered as a scalar value. Taking into account the dependence of the other quantities from the wavelength $\lambda$ leads to the following equation, assuming that only water vapour absorbs in the spectral region under consideration:

$\ln \frac{I_{j}^{\mathrm{M}}(\lambda)}{I_{0}^{\mathrm{M}}(\lambda)}=P_{j}(\lambda)-\sum_{i=j}^{N_{\text {layer }}} \tau_{i j}^{\mathrm{ref}}(\lambda) c_{i}\left(n_{i}\right) a_{i}$

Although water vapour absorption is dominant in the wavelength range used here $(928-968 \mathrm{~nm})$, ozone $\left(\mathrm{O}_{3}\right)$ is absorbing in the same spectral region. To improve the water vapour 
fit residuals, we also consider ozone as an absorber. Therefore, an additional sum of reference ozone optical depths $\tau_{i j}^{\mathrm{O}_{3} \text {,ref }}$, also derived from radiative transfer calculations and then scaled by a factor $b_{i}$, has to be taken into account. Note that no additional correction factors are required for ozone because convolution and non-linearity effects do not play a role here and we are not interested in the absolute ozone amounts. This results in the following relation:

$\ln \frac{I_{j}^{\mathrm{M}}(\lambda)}{I_{0}^{\mathrm{M}}(\lambda)}=P_{j}(\lambda)-\sum_{i=j}^{N_{\text {layer }}} \tau_{i j}^{\mathrm{ref}}(\lambda) c_{i}\left(n_{i}\right) a_{i}-\sum_{i=j}^{N_{\text {layer }}} \tau_{i j}^{\mathrm{O}_{3}, \text { ref }}(\lambda) b_{i}$

For a given non-linearity correction $c_{i}$ the coefficients of the polynomial $P_{j}$ and the scaling factors $a_{i}$ and $b_{i}$ (which do not depend on wavelength) can be determined via a least squares fit using Eq. (11). Note that $c_{i}$ is a function of $n_{i}$ and therefore also $a_{i}$. Consequently, $c_{i}$ needs to be adapted in each iteration step of the fit. The retrieval starts at the top tangent height $\left(j=N_{\text {layer }}\right)$, which results in the quantities $P_{N_{\text {layer }}}$ and the scaling factors $a_{N_{\text {layer }}}$ and $b_{N_{\text {layer }}}$. In the retrieval for the next lowest tangent altitude $\left(j=N_{\text {layer }}-1\right)$ the determined values for $a_{N_{\text {layer }}}$ and $b_{N_{\text {layer }}}$ are then used, and so on, such that for each tangent height $j$ only $a_{j}$ and $b_{j}$ (and the coefficients of $P_{j}$ ) need to be fitted. The water vapour density at a certain altitude $j$ is then given by:

$n_{j}=a_{j} n_{j}^{\mathrm{ref}}$

Obviously, one disadvantage of this method is that any errors of the higher tangent altitudes propagate downward. However, in the case of water vapour the coupling between the different layers is largely reduced by the exponential density increase with decreasing altitude.

\subsection{Determination of partial optical depths}

The partial optical depths $\tau_{i j}^{\text {ref }}$ and $\tau_{i j}^{\mathrm{O}_{3} \text {,ref }}$ can be derived from radiative transfer calculations. For this purpose, two transmission spectra need to be determined for an instrument looking at altitude $j$ :

1. A spectrum $I_{i j}$ assuming an atmosphere where only layer $i$ contains the absorber.

2. A spectrum $I_{j}^{0}$ assuming an atmosphere where the absorber is not present at all.

The partial optical depth is then given by:

$\tau_{i j}=\ln \frac{I_{j}^{0}}{I_{i j}}$

For the computation of the convolution correction according to Eq. (6) additionally the end-to-end spectra $I_{j}$ and $I_{0}$ are required. All spectra have been derived using the radiative transfer model SCIATRAN (Rozanov et al., 2002), Version 2.2 in transmission mode. The involved water vapour cross sections are taken from the HITRAN 2008 data base (Rothman et al., 2009). The assumed reference atmosphere contains pressure, temperature and water vapour concentrations taken from model data provided by the European Centre for Medium Range Weather Forecasts (ECMWF) for a latitude of $67.5^{\circ} \mathrm{N}$ and a longitude of $30^{\circ} \mathrm{W}$ on 10 November 2005 , 18:00 UT. This time and place corresponds to one of the collocations between SCIAMACHY and ACE-FTS (see below), but this is actually an arbitrary choice.

Because the retrieval uses a fixed set of reference optical depths and saturation correction factors, the retrieval results are somewhat sensitive to the choice of the reference atmosphere. This is mainly because the water vapour absorption cross section is a function of temperature and (to a lesser degree) pressure. Depending on the actual atmospheric conditions which usually differ from the model assumptions this may cause systematic deviations in the retrieved profiles. Retrieval studies with different model atmospheres have shown that this systematic effect is largest at lower altitudes where the deviations between the retrieved profiles may reach about $20 \%$ in extreme cases (e.g. when using a tropical atmosphere for a retrieval at higher latitudes). At altitudes above about $35 \mathrm{~km}$ there is almost no dependency on the reference atmosphere. The ECMWF model atmosphere used in this study is considered to be appropriate for the latitudinal range of the measurements (about $50-70^{\circ} \mathrm{N}$, see below), therefore no major systematic error contributions are expected from using a fixed background atmosphere.

The altitude grid for the radiative transfer calculations consists of $1 \mathrm{~km}$ intervals from 0 to to $50 \mathrm{~km}$ which is the maximum altitude for the retrieval. The reference atmosphere, however, continues further upwards, therefore the topmost model altitude level has no upper limit but contains everything above. Currently, the retrieval is limited to altitudes above $15 \mathrm{~km}$ because below this height (and especially in the troposphere) densities and related non-linear effects in the optical depths become too large and also refraction becomes more important such that the model assumptions are no longer valid.

Figure 2 shows some examples for modelled partial optical depths $\tau_{i j}^{\text {ref }}$ of water vapour for different combinations of water vapour layer altitude index $i$ and viewing altitude index $j$. In the case where the viewing altitude equals the layer which contains water vapour (Fig. 2a) the optical depth increases with decreasing altitude, as can be expected from the increasing water vapour concentration. For a fixed layer altitude (in Fig. 2b $50 \mathrm{~km}$ ) the optical depths decrease with decreasing viewing altitude because the absorber concentration along the light path decreases.

The partial optical depth shown in Fig. $2 \mathrm{a}$ and $\mathrm{b}$ contain a correction for the convolution effect described above. In the case of water vapour, this correction factor becomes significantly large especially for lower tangent altitudes, as can be seen from Fig. 2c. 


\subsection{Determination of saturation correction}

The saturation (or non-linearity) correction factor $c_{i}\left(n_{i}\right)$ is also determined from radiative transfer calculations using the relation

$\ln \frac{\left\langle I_{j}^{0}\right\rangle}{\left\langle I_{j}\right\rangle}=\sum_{i=j}^{N_{\text {layer }}} \tau_{i j}^{\text {ref }} a_{i} c_{i}$

which can be derived from Eq. (10) when taking modelled spectra instead of measured ones. Defining

$\tau_{j}:=\ln \frac{\left\langle I_{j}^{0}\right\rangle}{\left\langle I_{j}\right\rangle}$

and denoting with $\bar{x}$ the spectral average over the fitting window for quantity $x$, the following relation for the saturation correction can be derived:

$c_{j}=\frac{\overline{\tau_{j}}-\sum_{i=j+1}^{N_{\text {layer }}} \overline{\tau_{i j}^{\text {ref }}} a_{i} c_{i}}{a_{j} \overline{\tau_{j j}^{\text {ref }}}}$

Using Eq. (16), starting from the top altitude $\left(N_{\text {layer }}\right)$ and then propagating downwards each saturation correction factor for a certain tangent altitude can be derived. Note that $\tau_{j}$ is also a function of density, or the related scaling factors $a_{i}$. The density dependence of $c$ is derived by performing radiative transfer calculations for water vapour profiles which are scaled by a height independent factor. The resulting density dependence of $c$ is in fact an approximation, because as can be seen from Eq. (16) - the $c_{j}$ depend not only on the density in layer $j$ (i.e. $a_{j}$ ) but also on all densities (or $a_{i}$ ) above. Therefore, different shapes of profiles will result in a different density dependence of $c$. However, specifically for stratospheric water vapour this effect is considered to be small because of the exponential decrease of density with altitude which limits the impact of altitudes which are much higher than the tangent altitude.

This way, a data base of saturation correction factors $c_{i}\left(a_{i}\right)$ is calculated for a set of scaling factors between $10 \%$ and $300 \%$. In the retrieval, the required saturation correction factors are then derived by interpolation.

Figure 3a shows the derived saturation correction factor $c$ as function of the used water vapour profile scaling factor for different tangent altitudes. In general, a smaller scaling factor (i.e. lower water vapour densities than $n^{\text {ref }}$ ) results in a larger $c$ and vice versa. This is because $c_{i}$ is multiplied to the density scale factor in the retrieval formula (Eq. 11). For the reference atmosphere, the scaling factor and thus all $a_{i}$ are equal to 1 , yielding that also all $c_{i}$ are equal 1 (as it should be). For a tangent altitude of $50 \mathrm{~km}$ the saturation correction factor is close to 1 and does not depend much on the water vapour density. For lower tangent altitudes the saturation effect and also the density dependence becomes larger, although there is not much difference between the saturation correction factors for the lowest altitudes $(15 \mathrm{~km}$ and $20 \mathrm{~km})$. a)
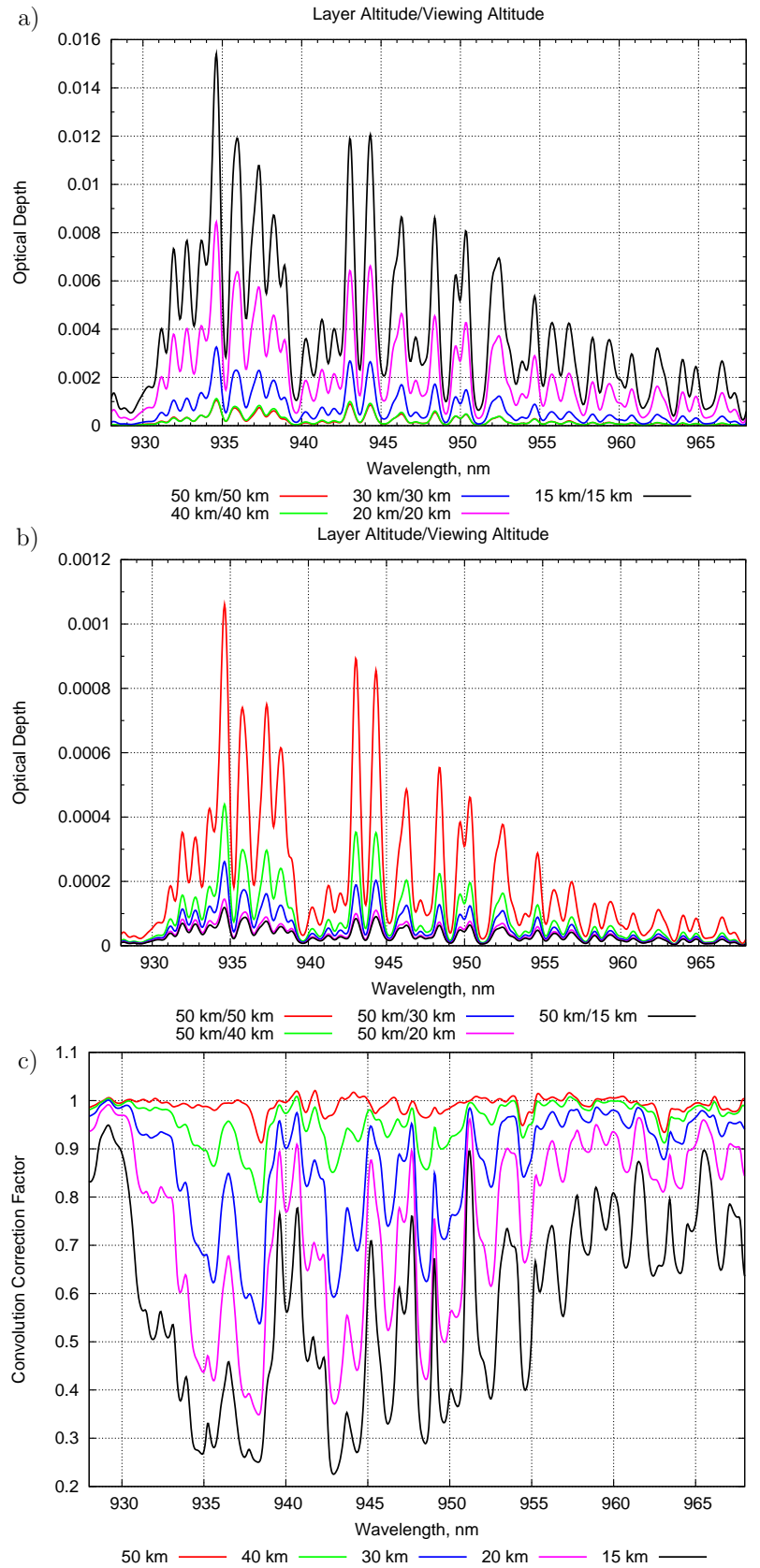

Fig. 2. Modelled partial optical depths (including convolution correction). The "layer altitude" is the only altitude containing water vapour. The "viewing altitude" corresponds to the observed tangent altitude. (a) Layer altitude equals viewing altitude. (b) Same layer altitude $(50 \mathrm{~km})$ but different viewing altitudes. (c) Convolution correction factor as function of wavelength for different tangent altitudes.

This can be explained by an increased influence of pressure broadening of the absorption lines at lower altitudes which reduces saturation effects. 

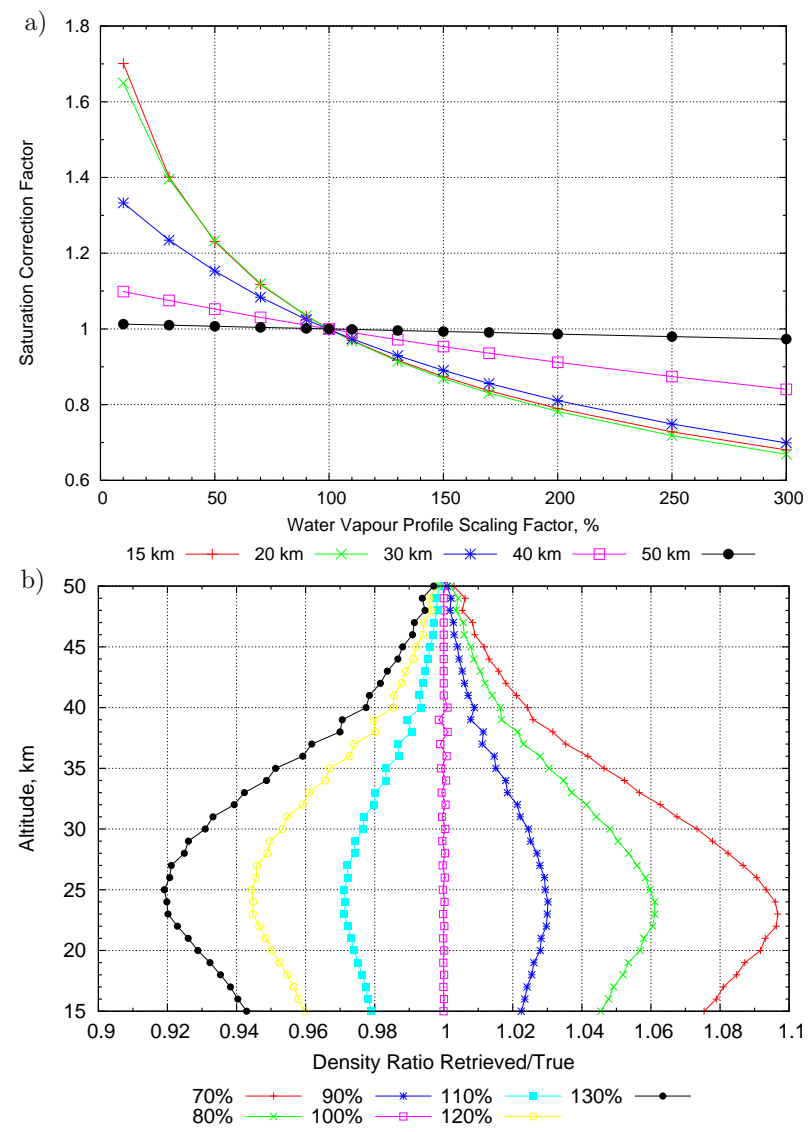

Fig. 3. Results for simulated data. (a) Saturation correction factors as function of the water vapour scaling factor for different tangent altitudes. (b) Results of a retrieval on simulated data using scaled water vapour profiles. The different curves correspond to different scaling factors.

\subsection{Consistency check}

A consistency check of the retrieval method is performed by application of Eq. (11) to simulated data, equivalent to those data from which the saturation correction factors are computed. The input water vapour profiles have been scaled by factors between $70 \%$ and $130 \%$, thus covering at least the expected variability of stratospheric water vapour which is in the order of $20 \%$. No additional noise has been added to the simulated data. The resulting ratios of the retrieved water vapour density profiles to the true one are plotted in Fig. 3b as function of altitude.

For a self-consistent retrieval the density ratio should be equal to 1 for all altitudes. As can be seen from Fig. 3b this is only the case for the reference density ( $100 \%$ scaling). For scaling factors different from 1 there are deviations of up to $\pm 10 \%$, increasing with the scale factor and with a maximum between 20 and $25 \mathrm{~km}$. The main reason for these differences is that the retrieval uses a scalar saturation correction factor instead of a spectrally resolved one. Because of this, the accuracy of the retrieval method described here is currently limited by the saturation correction to about $10 \%$.

Especially above about $30 \mathrm{~km}$ small oscillations in the retrieved ratios occur. This kind of oscillations is well known from limb or occultation profile retrievals (see e.g. v. Clarmann et al., 1991; Sofieva et al., 2004). One possibility to overcome this problem is to add constraints on the smoothness of the profile to the retrieval as a priori information. The retrieval method used in the present paper does not contain such smoothness constraints. Instead, the profiles resulting from SCIAMACHY measurements are smoothed after the retrieval considering the vertical resolution of the instrument. This is described in the next section.

\section{Application to SCIAMACHY}

The SCIAMACHY instrument performs solar occultation measurements usually once per orbit during sunrise ${ }^{1}$. With an orbital period of about $100 \mathrm{~min}$ this results in 14 to $15 \mathrm{oc}-$ cultation measurements per day. SCIAMACHY comprises eight channels of 1024 pixels each, covering almost continuously the spectral range between about $220 \mathrm{~nm}$ and $2400 \mathrm{~nm}$. In the spectral range of the water vapour retrieval (928 to $968 \mathrm{~nm}$ ) the spectral resolution is about $0.52 \mathrm{~nm}$. The SCIAMACHY instantaneous field of view (IFOV) in solar occultation mode is about $0.72^{\circ} \times 0.045^{\circ}$; this corresponds to a vertical resolution at the tangent point of about $2.6 \mathrm{~km}$. The horizontal resolution (across track) at the tangent point is about $30 \mathrm{~km}$, limited by the size of the sun (about $0.5^{\circ}$ ).

A solar occultation measurement is performed by SCIAMACHY in the following way: Before sunrise there are for $30 \mathrm{~s}$ vertical scans of $\pm 0.33^{\circ}$ around an altitude of about $17 \mathrm{~km}$. As soon as the centre of the sun reaches this altitude, the rising sun is followed upwards while continuing the upward/downward scans. Above $100 \mathrm{~km}$ there are different modes of solar occultation measurements performed; for the water vapour profile retrieval we use only those measurements where the vertical scan over the sun is continued up to almost $300 \mathrm{~km}$.

For the spectral range considered here there are 16 readouts per vertical scan (either downward or upward). For the retrieval a subset of these measurements is used; namely only those data when the sun is already rising but below $60 \mathrm{~km}$. Furthermore, only data from the central part of the upward scans are used. This results in about 20 spectra at different tangent altitudes between 0 and $60 \mathrm{~km}$. However, as explained in the previous section, retrieval results below $15 \mathrm{~km}$ are currently not used. This is illustrated in Fig. 4 for a typical SCIAMACHY solar occultation measurement. In addition, corresponding measurements at about $200 \mathrm{~km}$ altitude

\footnotetext{
${ }^{1}$ Note that although the SCIAMACHY instrument sees a rising sun, the local time at the tangent point is in the evening, i.e. corresponds to sunset.
} 
are used as reference spectrum $\left(I_{0}\right)$ by which the lower altitude spectra are divided; care is taken that only spectra of the same relative position on the sun (i.e. matching readouts in the vertical scan) are combined. This is necessary because of the different filling of the IFOV.

It is a prerequisite of the retrieval method used here that the modelled optical depths and the measured spectra are on the same altitude grid. To avoid a re-calculation of optical depths for each individual measurement the (logarithms of the) measured SCIAMACHY spectra are linearly interpolated to the retrieval altitude grid before the retrieval. After the retrieval, the derived profiles are smoothed by application of a boxcar filter of width $2.6 \mathrm{~km}$, which is the vertical size of the SCIAMACHY instantaneous field of view. This smoothing is done to avoid retrieval artefacts resulting from (1) instabilities/oscillations in the retrieved profiles due to a lack of information, (2) the interpolation of the measured transmissions to the (finer) retrieval altitude grid, and (3) the coarser vertical resolution of the SCIAMACHY measurements compared to the retrieval grid spacing of $1 \mathrm{~km}$.

\section{Results}

Figure 5 shows an example for retrieval results for a SCIAMACHY measurement in orbit 19333 on 10 November 2005. Panel a depicts the measured signal $\left(\ln I / I_{0}\right)$ at $50 \mathrm{~km}$ together with the fitted spectrum and the resulting relative residual. The signal at this altitude is low and noisy, and the residual is quite large, but nevertheless the fit is successful. Panel $b$ shows the same for a tangent altitude of $20 \mathrm{~km}$. Here, the densities are much higher and also the absorption structures are much better pronounced. Consequently, the relative fit residuals are much smaller. However, a closer look at the residuals reveals larger differences between fit and measurements at spectral regions where absorption is higher (e.g. around $935 \mathrm{~nm}$ ). This is an indication that saturation is not completely corrected, most likely because the currently implemented saturation correction does not depend on wavelength. Here, there is room for improvement of the retrieval method.

Figure 5c shows the retrieved profile of water vapour. The un-smoothed data are depicted by the blue line, the smoothed data by the red line. Below about $30 \mathrm{~km}$ there is almost no difference between the smoothed and un-smoothed profile. The green circles indicate the original measurement tangent heights. The error bars give the estimated retrieval error derived from the fit, which (in the logarithmic plot) increases with height and is considerably high (about 50\%) above $45 \mathrm{~km}$.

Up to now, all SCIAMACHY data from August 2002 until October 2009 have been processed using the Onion Peeling DOAS method. The resulting profiles are shown in Fig. 6a. For this plot all data of one day (up to 13 profiles at different longitudes but almost the same latitude) have been averaged.

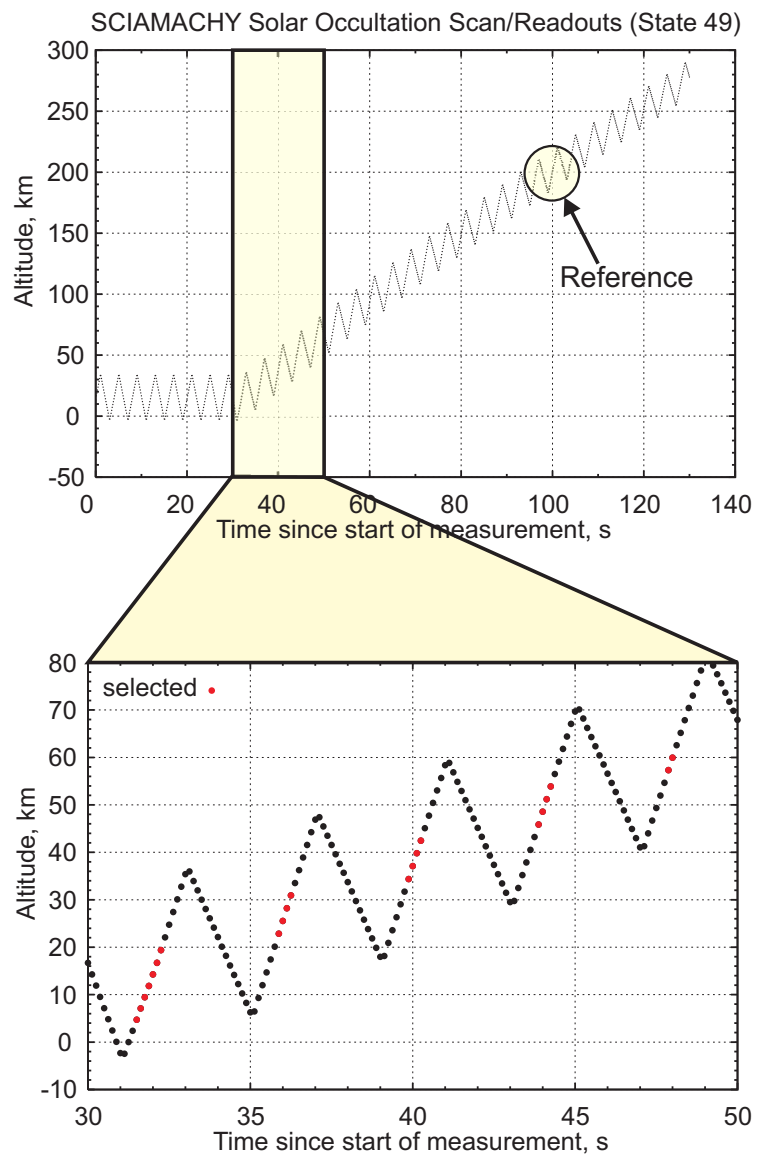

Fig. 4. Tangent altitudes of channel 5 readouts during a typical SCIAMACHY solar occultation measurement. Only those altitudes marked by red points are used in the retrieval. Reference spectra $\left(I_{0}\right)$ are taken from the upward scan around $100 \mathrm{~s}$ after the start of the measurement in about $200 \mathrm{~km}$ altitude.

The latitudinal distribution of the data is shown in the top of the figure. As can be seen from this, SCIAMACHY occultation measurements are restricted to northern mid-latitudes between about $50^{\circ}$ and $70^{\circ}$. Because of the sun-fixed ENVISAT orbit the latitudinal variation is the same for each year. The black curve in the lower part of the figure shows the average tropopause height (defined as temperature minimum), which has been derived from collocated ECMWF temperature profiles provided every $6 \mathrm{~h}$ on a $1.5^{\circ} \times 1.5^{\circ}$ latitude/longitude grid.

As can be seen from Fig. 6a, the water vapour number densities vary very smoothly with altitude; as expected, there is continuous decrease upwards. The seasonal variation roughly follows the variation of tropopause heights and/or tangent latitudes; this can not clearly be separated because both are coupled. In (northern) summer, tropopause heights are higher (and latitudes are lower), and the water vapour profiles are shifted upwards. 

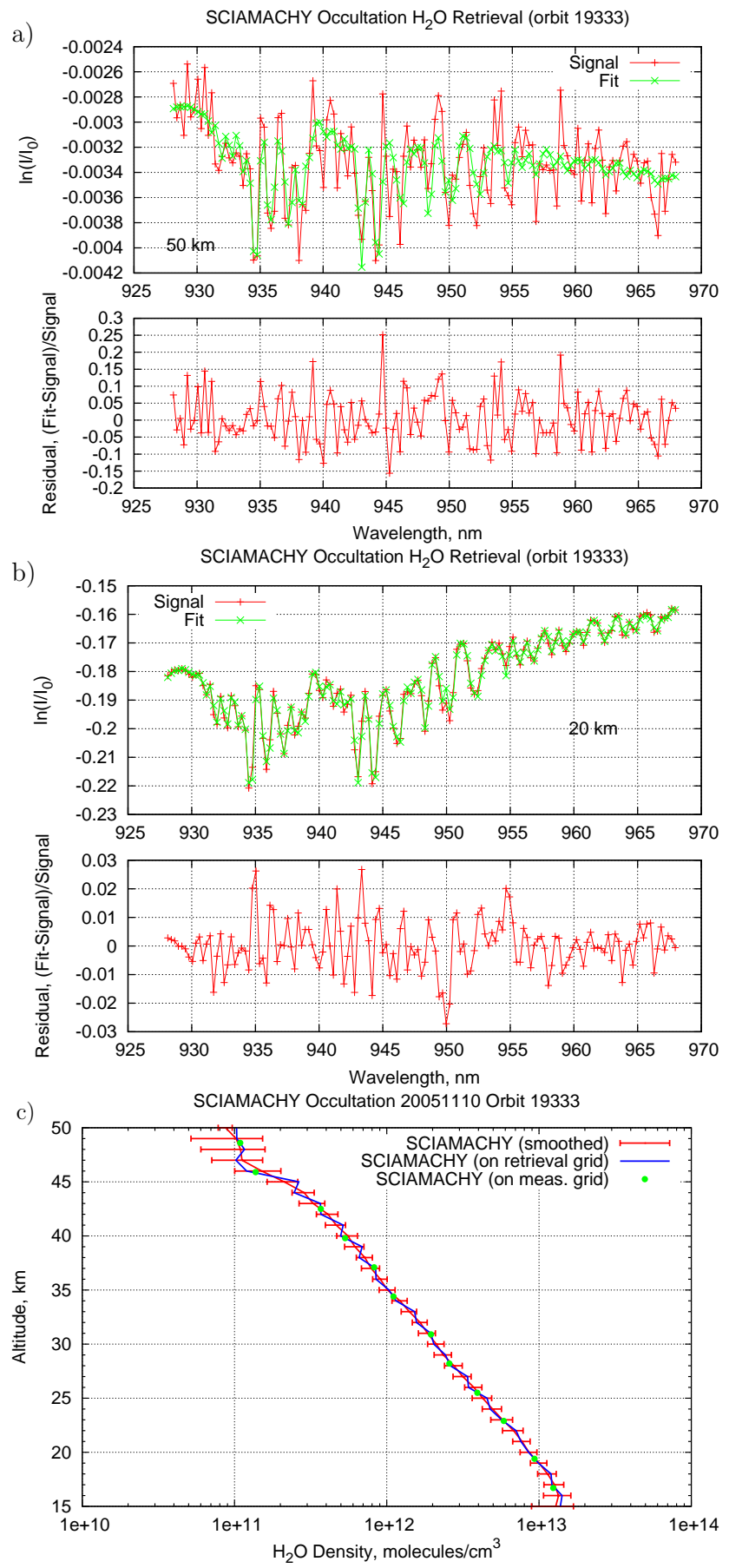

Fig. 5. Example fit results for a SCIAMACHY occultation measurement on 10 November 2005. (a) Measured signal and fit (top) and corresponding residual (bottom) for $50 \mathrm{~km}$ tangent altitude. (b) Same for $20 \mathrm{~km}$ tangent altitude. (c) Resulting water vapour profile from SCIAMACHY data (smoothed, un-smoothed, and interpolated to measurement altitude grid). a)

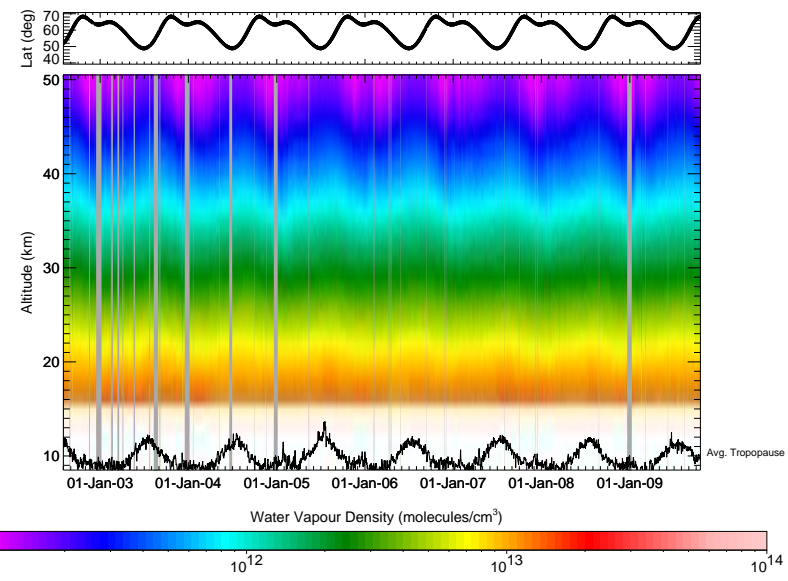

b)

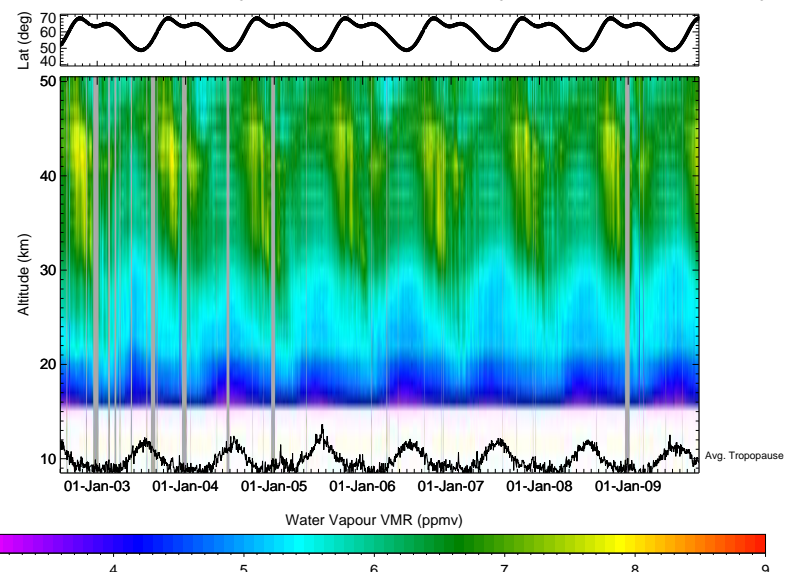

Fig. 6. Daily averaged water vapour profiles derived from SCIAMACHY occultation measurements with the Onion Peeling DOAS method. (a) Number density profiles. The latitudinal range of the SCIAMACHY measurements is indicated on top of the figures. The black curve shows the average tropopause height, derived from collocated ECMWF data. Periods of reduced SCIAMACHY data quality (due to instrument switch-offs or decontamination periods) have been masked out (vertical grey bars). (b) Same plot for volume mixing ratio (VMR) profiles.

In Fig. $6 \mathrm{~b}$ the same data set as in panel a is shown, but in form of volume mixing ratios (VMRs). The VMRs have been derived from the original SCIAMACHY number density profiles using collocated ECMWF pressure and temperature data (again on a $1.5^{\circ} \times 1.5^{\circ}$ latitude/longitude grid). Because pressure and temperature are taken from a different data set, the VMR profiles are somewhat noisier than the number density profiles. However, the seasonal variation and the relation to tropopause height/tangent latitude is very similar. Minimum VMRs occur below about $25 \mathrm{~km}$ (lowest in summer), whereas maximum values are reached between 40 and $45 \mathrm{~km}$. In this altitude region the measured VMRs are about $8 \mathrm{ppmv}$, which is in general agreement with other measurements and models (see e.g. Thornton et al., 2009). 


\section{Validation}

For a first validation, the derived SCIAMACHY water vapour profiles have been compared with collocated water vapour profiles from the European Centre for Medium Range Weather Forecasts (ECMWF) and from the Atmospheric Chemistry Experiment Fourier Transform Spectrometer (ACE-FTS).

The ECMWF water vapour density profile has been derived from analysed meteorological profiles of pressure, temperature and specific humidity, which are provided every $6 \mathrm{~h}$ on a $1.5^{\circ} \times 1.5^{\circ}$ latitude/longitude grid. The ECMWF profile closest in time and space has been selected.

The ACE-FTS instrument is the primary payload of the Canadian SCISAT-1 satellite which was launched in August 2003 (Bernath et al., 2005). ACE-FTS performs solar occultation measurements in the infrared spectral range (2.2 to $13.3 \mu \mathrm{m})$ and provides altitude profiles for temperature, pressure and the volume mixing ratios (VMRs) of several atmospheric molecules - including water vapour - between typically 10 and $100 \mathrm{~km}$. The second instrument on SCISAT-1, ACE-MAESTRO (Measurement of Aerosol Extinction in the Stratosphere and Troposphere Retrieved by Occultation) is a UV-Vis spectrometer which also provides - among other products - water vapour profiles. However, in the present paper we only compare with ACE-FTS profiles (Version 2.2). The ACE water vapour profiles have been validated by comparisons with results from several space-borne, balloon-borne and ground-based sensors (Carleer et al., 2008), resulting in an agreement within about $5-10 \%$ in the stratosphere (15 to $70 \mathrm{~km})$. For the comparison with SCIAMACHY data the VMRs have been converted to number densities using temperature and pressure profiles also provided by ACE-FTS. The criteria for collocated ACEFTS and SCIAMACHY data sets are that the data have to be obtained on the same day within a maximum tangent point distance of $500 \mathrm{~km}$. For the comparison all data have been interpolated to the SCIAMACHY retrieval altitude grid.

Figure 7 shows the (smoothed) SCIAMACHY water vapour profile from Fig. 5c in comparison with ECMWF and ACE-FTS data. In this case, the selected ACE-FTS profile is obtained at the same day as the SCIAMACHY data at almost the same location (distance only about $16 \mathrm{~km}$ ). The shown ECMWF profile is in fact the one which was used in the radiative transfer calculations to derive partial optical depths and saturation correction factors (see Sect. 2).

Whereas the ECMWF water vapour densities are systematically lower than both satellite data, there is a quite good agreement between the ACE-FTS and SCIAMACHY results. This is confirmed by a more extended analysis involving 408 collocations between SCIAMACHY and ACE-FTS and the corresponding ECMWF data in the years 2004 to 2007. The results of the inter-comparisons are shown in Fig. 8.

Figure $8 \mathrm{a}$ shows the average water vapour profiles of SCIAMACHY, ACE-FTS and ECMWF. Whereas the ACE-

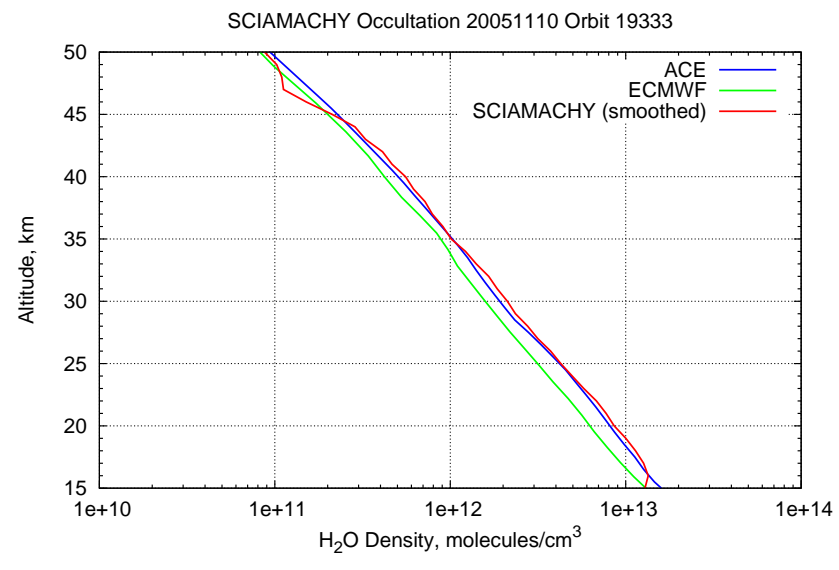

Fig. 7. SCIAMACHY water vapour profile on 10 November 2005. Comparison of SCIAMACHY water vapour profile from 10 November 2005 with matching ACE and ECMWF profiles.

FTS and SCIAMACHY data agree quite well over almost the whole altitude range, the mean ECMWF water vapour concentrations are systematically lower than both ACE-FTS and SCIAMACHY results at all altitudes. The error bars in Fig. 8a comprise the standard deviation of the profiles at each altitude and do not consider errors of the retrieved water vapour data. The errors bars therefore are an indicator for the variability in water vapour seen by the instruments and the model. For all data sets the variability is lowest between 20 and $25 \mathrm{~km}$ and increases at higher altitudes and towards the troposphere.

In panel $\mathrm{b}$ of Fig. 8 the correlation between the data sets (SCIAMACHY vs. ACE-FTS, SCIAMACHY vs. ECMWF and ACE-FTS vs. ECMWF) is shown as a function of altitude. The correlation describes how well variations in water vapour profiles by ACE-FTS or ECMWF are reproduced by the SCIAMACHY data, which is an important information to e.g. assess the potential to derive stratospheric water vapour trends. The observed correlation is very similar for all three combinations and considerably high at altitudes above $30 \mathrm{~km}$ (Pearson's $r$ varies around 0.7-0.9 there), but significantly drops down for lower altitudes. Above about $20 \mathrm{~km}$ these low correlations are possibly related to the smaller water vapour variations at these altitudes, as can be seen from the standard deviations in panel a. Below $20 \mathrm{~km}$ variations become higher; there, atmospheric effects like refraction (which is not considered in the SCIAMACHY retrieval) may play a role. This has to be investigated further.

Panel $\mathrm{c}$ of Fig. 8 shows the mean relative difference between the SCIAMACHY and ACE-FTS results (related to the mean of both data sets, i.e. (SCIA+ACE)/2) as function of height and the corresponding standard deviations of the differences. Figure $8 \mathrm{~d}$ is a similar plot for the comparison with ECMWF; reference is here also the mean, i.e. $(\mathrm{SCIA}+\mathrm{ECMWF}) / 2$. 

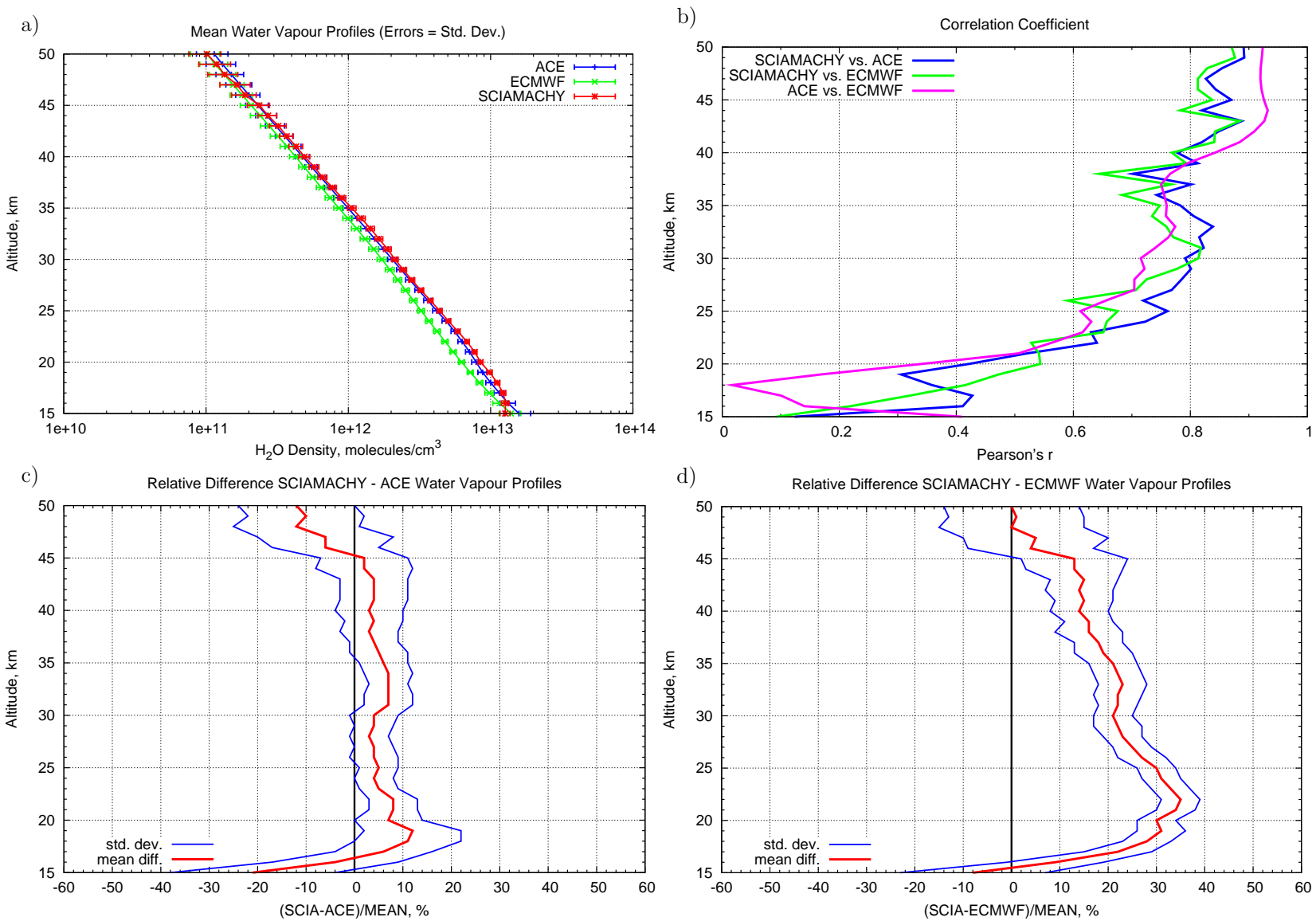

Fig. 8. Results of comparison between 408 collocated SCIAMACHY, ACE-FTS and ECMWF water vapour profiles. (a) Mean profiles; the error bars denote the standard deviation of the profiles. (b) Correlation between profiles as function of altitude. (c) Mean relative deviation between SCIAMACHY and ACE-FTS profiles and corresponding standard deviation. (d) As (c), but for comparison with ECMWF data.

As can be seen from Fig. 8c, the SCIAMACHY water vapour concentrations are systematically higher than the ACE-FTS values by about $5 \%$ between 20 and $45 \mathrm{~km}$. Below and above this altitude range deviations are somewhat larger. As noted before, the results above $45 \mathrm{~km}$ are associated with a significant retrieval error and therefore less reliable. Below about $18 \mathrm{~km}$ the SCIAMACHY water vapour densities decrease significantly as can also be seen in subpanel a. This is considered to be related to tropospheric effects which limit the applicability of the SCIAMACHY retrieval at lower altitudes. The standard deviation of the differences is only about $5 \%$ except for the lowest and highest altitudes where it reaches about $10-15 \%$

The comparison with ECWMF data (Fig. 8d) confirms a systematic positive offset between SCIAMACHY and ECMWF water vapour profiles of about 15 to $35 \%$, largest between 20 and $25 \mathrm{~km}$. The standard deviation is except for the highest altitudes again small (5-10\%).

\section{Discussion of errors}

To judge upon the quality of the SCIAMACHY water vapour density data various error sources of the retrieval (most of them mentioned before) are summarised and discussed in this section.

The precision of the derived water vapour densities estimated from the residuals of the retrieval (when applied to real measurement data) is typically in the order of $10-20 \%$ below $45 \mathrm{~km}$ (see Fig. 5 for an example) and usually below $15 \%$ between 20 and $40 \mathrm{~km}$. This includes random error components resulting from instrumental noise.

As described in Sect. 2.6 the retrieval has shown to be self-consistent on a sub-percent level, i.e. if a retrieval is performed on the same simulated data which were used to derive the radiative transfer data base the correct profile is retrieved. Artificial oscillations in the retrieved profiles caused by the retrieval are expected to be largely reduced by the applied vertical smoothing and thus of minor importance. 
However, systematic offsets are expected due to insufficiencies of the (scalar) saturation correction (see Fig. 3). The actual error which results from this depends on how large the 'true' atmospheric conditions differ from the ones assumed in the radiative transfer calculations. Taking into account typical variabilities of water vapour as shown in Fig. 6 the maximum error due to limited saturation correction is estimated to be about $10 \%$ at around $25 \mathrm{~km}$. This error is currently considered to be the major source of uncertainties for the water vapour product. Because the chosen atmospheric conditions in the radiative transfer are based on ECMWF data, they are considered to be quite representative such that the specific choice of the reference profiles should (on average) have only a minor impact on the retrieval results.

Another potential systematic error, not mentioned before, arises from the SCIAMACHY pointing knowledge, i.e. the accuracy of the tangent heights. Currently, SCIAMACHY tangent heights are expected to be accurate within some $100 \mathrm{~m}$ (with some seasonal effects), which translates into an error of water vapour densities in the order of $1-3 \%$.

Other potential systematic error sources are the selected slit function and the knowledge of the line parameters given in the HITRAN (Rothman et al., 2009) data base used in the radiative transfer calculations. These errors are difficult to quantify, but since the most actual data have been used in the retrieval this error is considered to be small.

Based on the values given above, the overall uncertainty of the SCIAMACHY water vapour densities for a single measurement is expected to be in the order of $10-15 \%$.

The accuracy of the water vapour product can only be assessed after validation. Based on the comparison with ACEFTS data shown in Sect. 5 an accuracy of the SCIAMACHY water vapour profiles of about $5 \%$ (mean deviation, with a standard deviation of also about $5 \%$ ) in the altitude range 20 to $45 \mathrm{~km}$ is estimated.

\section{Conclusions}

The new "Onion Peeling DOAS" retrieval method to derive water vapour density profiles from SCIAMACHY solar occultation measurements in the spectral region $928-968 \mathrm{~nm}$ has shown to provide reasonable results in the altitude region $15-45 \mathrm{~km}$. The estimated precision of the SCIAMACHY water vapour profiles is 10 to $20 \%$ in this altitude range and typically better than $15 \%$ between 20 and $40 \mathrm{~km}$. ECMWF water vapour densities are generally lower than both ACEFTS and SCIAMACHY data at all heights. The maximum deviation between SCIAMACHY and ECMWF results is about $35 \%$ between 20 and $25 \mathrm{~km}$. Comparisons with ACEFTS show a quite good agreement at altitudes between 20 and $45 \mathrm{~km}$ where mean relative deviations are below about $5 \%$, with SCIAMACHY results being typically larger than those of ACE-FTS. Based on this, an accuracy of the SCIAMACHY product of about $5 \%( \pm 5 \%)$ is estimated. This is within the estimated systematic errors of the SCIAMACHY retrieval which are in the order of $10-15 \%$, mainly limited by the handling of saturation effects. For comparison, ACE validation results (Carleer et al., 2008) show an agreement of ACE-FTS water vapour profiles with other data sets in the stratosphere (15 to $70 \mathrm{~km})$ of about $5-10 \%$, which is in line with the SCIAMACHY data. Especially at higher altitudes there is a good correlation between the ACE-FTS and SCIAMACHY profiles, indicating that both instruments are capable to identify similar changes in water vapour concentrations. Taking into account the simplicity of the SCIAMACHY retrieval method, which (intentionally) only uses a very limited radiative transfer data base, these results are very promising.

In principle, the Onion Peeling DOAS method is not restricted to the application to water vapour. It may also be used for the retrieval of other trace gases (like ozone) where saturation is less critical. This will be investigated in the future.

Acknowledgements. SCIAMACHY is a national contribution to the ESA ENVISAT project, funded by Germany, The Netherlands, and Belgium. SCIAMACHY data have been provided by ESA. The Atmospheric Chemistry Experiment (ACE), also known as SCISAT, is a Canadian-led mission mainly supported by the Canadian Space Agency and the Natural Sciences and Engineering Research Council of Canada. We thank the European Center for Medium Range Weather Forecasts (ECMWF) for providing us with analysed meteorological fields. This work has been funded by DLR Space Agency (Germany), grant 50EE0727, and by the University of Bremen.

Edited by: R. Sussmann

\section{References}

Amekudzi, L., Bracher, A., Meyer, J., Rozanov, A., Bovensmann, H., and Burrows, J.: Lunar occultation with SCIAMACHY: First retrieval results, Adv. Space Res., 36, 906-914, doi:10.1016/j. asr.2005.03.017, 2005.

Aumann, H. H., Chahine, M. T., Gautier, C., Goldberg, M. D., Kalnay, E., McMillin, L. M., Revercomb, H., Rosenkranz, P. W., Smith, W. L., Staelin, D. H., Strow, L. L., and Susskind, J.: AIRS/AMSU/HSB on the Aqua Mission: Design, Science Objectives, Data Products, and Processing Systems, IEEE Trans. Geosc. Rem. Sens., 41, 253-264, doi:10.1109/TGRS.2002.808356, 2003.

Barnes, J. E., Kaplan, T., Vömel, H., and Read, W. G.: NASA/Aura/Microwave Limb Sounder water vapor validation at Mauna Loa Observatory by Raman lidar, J. Geophys. Res., 113, D15S03, doi:10.1029/2007JD008842, 2008.

Bernath, P. F., McElroy, C. T., Abrams, M. C., Boone, C. D., Butler, M., Camy-Peyret, C., Carleer, M., Clerbaux, C., Coheur, P.-F., Colin, R., DeCola, P., DeMazière, M., Drummond, J. R., Dufour, D., Evans, W. F. J., Fast, H., Fussen, D., Gilbert, K., Jennings, D. E., Llewellyn, E. J., Lowe, R. P., Mahieu, E., McConnell, J. C., McHugh, M., McLeod, S. D., Michaud, R., Midwinter, C., Nassar, R., Nichitiu, F., Nowlan, C., Rinsland, C. P., 
Rochon, Y. J., Rowlands, N., Semeniuk, K., Simon, P., Skelton, R., Sloan, J. J., Soucy, M.-A., Strong, K., Tremblay, P., Turnbull, D., Walker, K. A., Walkty, I., Wardle, D. A., Wehrle, V., Zander, R., and Zou, J.: Atmospheric Chemistry Experiment (ACE): Mission overview, Geophys. Res. Lett., 32, L15S01, doi: 10.1029/2005GL022386, 2005.

Bovensmann, H., Burrows, J. P., Buchwitz, M., Frerick, J., Noël, S., Rozanov, V. V., Chance, K. V., and Goede, A. H. P.: SCIAMACHY - Mission Objectives and Measurement Modes, J. Atmos. Sci., 56, 127-150, 1999.

Burrows, J. P., Weber, M., Buchwitz, M., Rozanov, V., LadstätterWeißenmayer, A., Richter, A., de Beek, R., Hoogen, R., Bramstedt, K., Eichmann, K.-U., Eisinger, M., and Perner, D.: The Global Ozone Monitoring Experiment (GOME): Mission Concept and First Scientific Results, J. Atmos. Sci., 56, 151-175, 1999.

Carleer, M. R., Boone, C. D., Walker, K. A., Bernath, P. F., Strong, K., Sica, R. J., Randall, C. E., Vömel, H., Kar, J., Höpfner, M., Milz, M., von Clarmann, T., Kivi, R., Valverde-Canossa, J., Sioris, C. E., Izawa, M. R. M., Dupuy, E., McElroy, C. T., Drummond, J. R., Nowlan, C. R., Zou, J., Nichitiu, F., Lossow, S., Urban, J., Murtagh, D., and Dufour, D. G.: Validation of water vapour profiles from the Atmospheric Chemistry Experiment (ACE), Atmos. Chem. Phys. Discuss., 8, 4499-4559, 2008, http://www.atmos-chem-phys-discuss.net/8/4499/2008/.

Carlotti, M.: Global-fit approach to the analysis of limb-scanning atmospheric measurements, Appl. Opt., 27, 3250-3254, doi:10. 1364/AO.27.003250, 1988.

Dhomse, S., Weber, M., and Burrows, J.: The relationship between tropospheric wave forcing and tropical lower stratospheric water vapor, Atmos. Chem. Phys., 8, 471-480, 2008, http://www.atmos-chem-phys.net/8/471/2008/.

Fischer, H., Birk, M., Blom, C., Carli, B., Carlotti, M., von Clarmann, T., Delbouille, L., Dudhia, A., Ehhalt, D., Endemann, M., Flaud, J. M., Gessner, R., Kleinert, A., Koopman, R., Langen, J., López-Puertas, M., Mosner, P., Nett, H., Oelhaf, H., Perron, G., Remedios, J., Ridolfi, M., Stiller, G., and Zander, R.: MIPAS: an instrument for atmospheric and climate research, Atmos. Chem. Phys., 8, 2151-2188, 2008,

http://www.atmos-chem-phys.net/8/2151/2008/.

Hagan, D. E., Webster, C. R., Farmer, C. B., May, R. D., Herman, R. L., Weinstock, E. M., Christensen, L. E., Lait, L. R., and Newman, P. A.: Validating AIRS upper atmosphere water vapor retrievals using aircraft and balloon in situ measurements, Geophys. Res. Lett., 31, L21103, doi:10.1029/2004GL020302, 2004.

Kühl, S., Pukite, J., Deutschmann, T., Platt, U., and Wagner, T.: SCIAMACHY limb measurements of $\mathrm{NO}_{2}, \mathrm{BrO}$ and OClO. Retrieval of vertical profiles: Algorithm, first results, sensitivity and comparison studies, Adv. Space Res., 42, 1747-1764, doi: 10.1016/j.asr.2007.10.022, 2008.

Kyrölä, E., Tamminen, J., Leppelmeier, G. W., Sofieva, V., Hassinen, S., Bertaux, J. L., Hauchecorne, A., Dalaudier, F., Cot, C., Korablev, O., Fanton d'Andon, O., Barrot, G., Mangin, A., Théodore, B., Guirlet, M., Etanchaud, F., Snoeij, P., Koopman, R., Saavedra, L., Fraisse, R., Fussen, D., and Vanhellemont, F.: GOMOS on Envisat: an overview, Adv. Space Res., 33, 10201028, 2004.

Meyer, J., Bracher, A., Rozanov, A., Schlesier, A. C., Bovensmann,
H., and Burrows, J. P.: Solar occultation with SCIAMACHY: algorithm description and first validation, Atmos. Chem. Phys., 5, 1589-1604, 2005, http://www.atmos-chem-phys.net/5/1589/2005/.

Milz, M., Clarmann, T. v., Bernath, P., Boone, C., Buehler, S. A., Chauhan, S., Deuber, B., Feist, D. G., Funke, B., Glatthor, N., Grabowski, U., Griesfeller, A., Haefele, A., Höpfner, M., Kämpfer, N., Kellmann, S., Linden, A., Müller, S., Nakajima, H., Oelhaf, H., Remsberg, E., Rohs, S., Russell III, J. M., Schiller, C., Stiller, G. P., Sugita, T., Tanaka, T., Vömel, H., Walker, K., Wetzel, G., Yokota, T., Yushkov, V., and Zhang, G.: Validation of water vapour profiles (version 13) retrieved by the IMK/IAA scientific retrieval processor based on full resolution spectra measured by MIPAS on board Envisat, Atmos. Meas. Tech., 2, 379399, 2009,

http://www.atmos-meas-tech.net/2/379/2009/.

Murtagh, D., Frisk, U., Merino, F., Ridal, M., Jonsson, A., Stegman, J., Witt, G., Eriksson, P., Jiménez, C., Megie, G., de la Noë, J., Ricaud, P., Baron, P., Pardo, J. R., Hauchcorne, A., Llewellyn, E. J., Degenstein, D. A., Gattinger, R. L., Lloyd, N. D., Evans, W. F., McDade, I. C., Haley, C. S., Sioris, C., von Savigny, C., Solheim, B. H., McConnell, J. C., Strong, K., Richardson, E. H., Leppelmeier, G. W., Kyrölä, E., Auvinen, H., and Oikarinen, L.: An overview of the Odin atmospheric mission, Can. J. Phys., 80, 309-319, doi:10.1139/P01-157, 2002.

Nedoluha, G. E., Bevilacqua, R. M., Hoppel, K. W., Lumpe, J. D., and Smit, H.: Polar Ozone and Aerosol Measurement III measurements of water vapor in the upper troposphere and lowermost stratosphere, J. Geophys. Res., 107, 4103, doi:10.1029/ 2001JD000793, 2002.

Noël, S., Buchwitz, M., and Burrows, J. P.: First retrieval of global water vapour column amounts from SCIAMACHY measurements, Atmos. Chem. Phys., 4, 111-125, 2004,

http://www.atmos-chem-phys.net/4/111/2004/.

Noël, S., Buchwitz, M., Bovensmann, H., and Burrows, J. P.: Validation of SCIAMACHY AMC-DOAS water vapour columns, Atmos. Chem. Phys., 5, 1835-1841, 2005, http://www.atmos-chem-phys.net/5/1835/2005/.

Palm, M., v. Savigny, C., Warneke, T., Velazco, V., Notholt, J., Künzi, K., Burrows, J., and Schrems, O.: Intercomparison of $\mathrm{O}_{3}$ profiles observed by SCIAMACHY and ground based microwave instruments, Atmos. Chem. Phys., 5, 2091-2098, 2005, http://www.atmos-chem-phys.net/5/2091/2005/.

Perner, D. and Platt, U.: Detection of Nitrous Acid in the Atmosphere by Differential Optical Absorption, Geophys. Res. Lett., 6, 917-920, 1979.

Piters, A. J. M., Bramstedt, K., Lambert, J.-C., and Kirchhoff, B.: Overview of SCIAMACHY validation: 2002-2004, Atmos. Chem. Phys., 6, 127-148, 2006,

http://www.atmos-chem-phys.net/6/127/2006/.

Rodgers, C. D.: Characterization and Error Analysis of Profiles Retrieved From Remote Sounding Measurements, J. Geophys. Res., 95, 5587-5595, 1990.

Rothman, L., Gordon, I., Barbe, A., Benner, D. C., Bernath, P. F., Birk, M., Boudon, V., Brown, L., Campargue, A., Champion, J.P., Chance, K., Coudert, L., Dana, V., Devi, V., Fally, S., Flaud, J.-M., Gamache, R. R., Goldman, A., Jacquemart, D., Kleiner, I., Lacome, N., Lafferty, W. J., Mandin, J.-Y., Massie, S. T., Mikhailenko, S. N., Miller, C. E., Moazzen-Ahmadi, N., Nau- 
menko, O. V., Nikitin, A. V., Orphal, J., Perevalov, V. I., Perrin, A., Predoi-Cross, A., Rinsland, C., Rotger, M., Simecková, M., Smith, M. A. H., Sung, K., Tashkun, S. A., Tennyson, J., Toth, R. A., Vandaele, A. C., and Auwera, J. V.: The HITRAN 2008 molecular spectroscopic database, J. Quant. Spectr. Rad. Transf., 110, 533-572, doi:10.1016/j.jqsrt.2009.02.013, 2009.

Rozanov, A., Bovensmann, H., Bracher, A., Hrechanyy, S., Rozanov, V., Sinnhuber, M., Stroh, F., and Burrows, J.: $\mathrm{NO}_{2}$ and $\mathrm{BrO}$ vertical profile retrieval from SCIAMACHY limb measurements: Sensitivity studies, Adv. Space Res., 36, 846-854, doi:10.1016/j.asr.2005.03.013, 2005.

Rozanov, A., Eichmann, K.-U., von Savigny, C., Bovensmann, H., Burrows, J. P., von Bargen, A., Doicu, A., Hilgers, S., GodinBeekmann, S., Leblanc, T., and McDermid, I. S.: Comparison of the inversion algorithms applied to the ozone vertical profile retrieval from SCIAMACHY limb measurements, Atmos. Chem. Phys., 7, 4763-4779, 2007, http://www.atmos-chem-phys.net/7/4763/2007/.

Rozanov, V. V., Buchwitz, M., Eichmann, K.-U., de Beek, R., and Burrows, J. P.: SCIATRAN - a new radiative transfer model for geophysical applications in the $240-2400 \mathrm{~nm}$ spectral region: The pseudo-spherical version, Adv. Space Res., 29, 1831-1835, 2002.

Russell, III, J. M. and Drayson, S. R.: The Inference of Atmospheric Ozone Using Satellite Horizon Measurements in the $1042 \mathrm{~cm}^{-1}$ Band, J. Atmos. Sci., 29, 376-390, 1972.

Russell, III, J. M., Gordley, L. L., Park, J. H., Drayson, S. R., Hesketh, W. D., Cicerone, R. J., Tuck, A. F., Frederick, J. E., Harries, J. E., and Crutzen, P. J.: The Halogen Occultation Experiment, J. Geophys. Res., 98, 10777-10797, 1993.
Sofieva, V. F., Tamminen, J., Haario, H., Kyrölä, E., and Lehtinen, M.: Ozone profile smoothness as a priori information in the inversion of limb measurements, Ann. Geophys., 22, 3411-3420, 2004 , http://www.ann-geophys.net/22/3411/2004/.

Thomason, L. W., Burton, S. P., Iyer, N., Zawodny, J. M., and Anderson, J.: A revised water vapor product for the Stratospheric Aerosol and Gas Experiment (SAGE) II version 6.2 data set, J. Geophys. Res., 109, doi:10.1029/2003JD004465, 2004.

Thomason, L. W., Poole, L. R., and Randall, C. E.: SAGE III aerosol extinction validation in the Arctic winter: comparisons with SAGE II and POAM III, Atmos. Chem. Phys., 7, 14231433, 2007, http://www.atmos-chem-phys.net/7/1423/2007/.

Thornton, H. E., Jackson, D. R., Bekki, S., Bormann, N., Errera, Q., Geer, A. J., Lahoz, W. A., and Rharmili, S.: The ASSET intercomparison of stratosphere and lower mesosphere humidity analyses, Atmos. Chem. Phys., 9, 995-1016, 2009, http://www.atmos-chem-phys.net/9/995/2009/.

Urban, J., Lautié, N., Murtagh, D., Eriksson, P., Kasai, Y., Loßowc, S., Dupuy, E., de La Noë, J., Frisk, U., Olberg, M., Flochmoën, E. L., and Ricaud, P.: Global observations of middle atmospheric water vapour by the Odin satellite: An overview, Planet. Space Sci., 55, 1093-1102, doi:10.1016/j.pss.2006.11.021, 2007.

v. Clarmann, T., Fischer, H., and Oelhaf, H.: Instabilities in retrieval of atmospheric trace gas profiles caused by the use of atmospheric level models, Appl. Opt., 30, 2924-2925, doi: 10.1364/AO.30.002924, 1991. 